\title{
Effect and Significance of Standardization on Marketing of Large and Medium-sized Enterprises
}

\author{
Jun Yuan \\ Guangdong Baiyun University, Guangzhou, 510450, China
}

\begin{abstract}
Keywords: Standardization. Marketing planning of large and medium-sized enterprises. Economic benefit. Effect And significance of standardization
\end{abstract}

\begin{abstract}
As market competitions become increasingly fierce, a good marketing strategy decides whether an enterprise can continuously develop. In recent years, influenced by global economic internationalization, various national markets have been open. In Chinese market, a large batch of multinational corporations which regard multinational corporations and even global market as the strategic target emerge. How to keep a foothold in huge competition tide and develop continuously and scientifically? From the perspective of large and medium-sized enterprises, standardized production not just contributes to reducing enterprise production and management cost, but also can effectively improve production benefit.
\end{abstract}

\section{Significance of large and medium-sized enterprises and the classification standard}

The standards of large and medium-sized enterprises are jointly studied and formulated by State Economic and Trade Commission, State Development Planning Commission, Ministry of Finance and State Statistics Bureau. The standards classify large and medium-sized enterprises in accordance with the number of employees, product sales revenue and total assets. The enterprises with the number of employees exceeding 300, product sales revenue exceeding RMB 30 million and total assets exceeding RMB 40 million are called medium-sized enterprises. The enterprises with the number of employees exceeding 2000, product sales revenue exceeding RMB 300 million and total assets exceeding RMB 400 million are called large enterprises.

\section{Concept of marketing standardization}

Marketing refers to marketing behaviors carried out in multiple countries by enterprises in order to realize global development. Compared with the marketing idea of pursuing market benefit maximization, marketing standardization pays more attention to integration and multinational cooperation so as to finally gain overall interests. It is the most effective control method integrating the most advanced management idea and the most successful management experience. Practice has proved that it is the most advanced management mode. Besides, it is approved by various countries in the world.

\section{Causes for preparing enterprise marketing planning and the direction}

\section{Analysis from the perspective of competitors}

Every large, medium-sized enterprise and even a small enterprise have their own competitors. The enterprise requires finding its disadvantages and advantages within effective time and widening the gap with competitors through improving shortcomings and giving play to advantages. Enterprises should compare advantages and disadvantages while analyzing competitors and assume the current strategy and future objective of competitors. In this way, enterprises can clearly see what the competitors are doing and plan to do and discover the opportunity for sustainable development so as to make the enterprises in the favorable position in competitions. 


\section{Analysis from the perspective of consumers}

Micro-factors of product demands are mainly analyzed from the perspective of consumers, mainly including: hobby, income level, feeling, consumption custom, consumer psychology and national habit etc. These factors can to a large extent judge whether enterprise products are accepted by most consumers. Thus, the consumption results directly influence the sales result of the enterprise. Therefore, it is necessary to judge consumption preferences of most consumers according to consumers' consumption factors and expand the consumption group according to the factor so as to increase enterprise sales amount.

\section{Analysis from the perspective of social cultural environment}

Human beings live in different societies. Different cultures will be bound to form. Different countries, different regions, different societies and different customs represent different modes of life. In other words, human beings will have different opinions on the same product. So, it is required to attach importance to survey and investigation of social culture and prepare proper marketing strategies during preparing marketing activities. Social culture includes educational level, language, values and customs etc.

\section{Analysis from the perspective of natural geographical environment}

For China, there are differences in the north and south. The differences are mainly reflected in season, temperature, climate and landform. Enterprises must consider these differences when carrying out marketing. The property and use of products produced by some large and medium-sized enterprises will be influenced.

\section{Analysis from the perspective of political and legal environment}

Enterprise marketing activities will inevitably be influenced by political factor. It adjusts the direction of enterprise marketing activities like an intangible hand. Enterprise marketing activities and standards of behaviors must follow laws and regulations and pay attention to their effects on marketing activities. Political situation, policies, guidelines, international relation and legal environment will influence the direction of enterprise marketing activities. Enterprises should know and flow these.

\section{Composition of enterprise marketing environment}

\section{Enterprise}

The enterprise is a main constituent part of marketing environment. One of important conditions for enterprise marketing is favorable and solid internal force in the enterprise. Internal force consists of senior management (such as president, factory director and shareholder) and various subordinate departments (such as purchase, technological development, design, project development, finance and production). According to operation directions of each enterprise, internal organizations are also different. Labor division and cooperation among each management will influence marketing management decision and implementation of marketing programs.

\section{Supplier}

Compared with other industrial leaders, suppliers have their own scope of work, i.e. provide products and services for buyers and finally gain currency as the remuneration. Suppliers are enterprises or individuals providing raw materials, equipment, energy, funds and other resources for the enterprise in order to guarantee product quality, maximized sales profit and rational price.

\section{Marketing intermediary (third party)}

It is an indispensable link in marketing. Most marketing activities need the help of marketing intermediaries who assist the enterprise in promoting and marketing the products to final consumers or other enterprises. Dealing with cooperation relationship with them well can not just proceed smoothly, but also maximize the effects of enterprise marketing planning. Therefore, as market economy develops and social labor division becomes increasingly detailed, the effects and influences of these intermediaries will become larger and larger. 


\section{Consumer}

Consumers are the target market. They are not just the object of enterprise service, but also the main impetus source for the enterprise to prepare marketing planning. Enterprise marketing activities focus on customers. In the market, consumers continuously raise consumption demands and change the demands. Enterprises can meet consumer demand only through continuously updating or designing new products. Enterprises should not just innovate continuously in order to satisfy customers, but also maintain old consumers. In this way, they will not be eliminated in fierce competitions. Consumers are the "god" of enterprises.

\section{Competitor}

Enterprise marketing activities are influenced by various competitors. So, enterprises should be good at discovering the shortcomings of competitors and perfect their marketing activity planning through utilizing competitors' strengths.

\section{Economic benefit brought by standardization}

\section{Standardization is the foundation of management scientification}

The establishment and operation of enterprise standard system can improve enterprise management level, work efficiency and overall cooperation ability and drive enterprise management standardization, order and scientification.

\section{Main functions of standardization}

1). It is beneficial to management of production process, reflected in providing product information, popularizing technology, boosting productivity, standardizing competition environment and ensuring interchangeability.

2). It can promote production, circulation and abandonment of standard products, enhance social benefit and contribute to protecting the environment, ensuring safety, saving energy and protecting consumers' standards.

3). It can promote action rules understood mutually.

\section{Standardization management}

Standardization management is an activity to gain the best order and formulate rules fir practical or potential problems within the scope of enterprise production and management. Standardization management mainly includes technical standard and management standard which ensure to give play to the functions of enterprise management system.

\section{Technical standard}

Technical standard is the best solution gained in the process of long-term technical level and practical experience. Uniform technical criteria are needed in technical activities for coordination.

\section{Management standard}

Management standard provides management activities, personnel and business management formulated by the enterprise in order to ensure product quality, improve product quality and achieve product quality objective.

\section{Safety standard}

Safety standard is formulated in order to prevent and reduce accidents and change previous poor production and management so as to achieve continuous and stable safety in production.

\section{Purpose of standardization}

\section{Educational training}

In a bid to produce even product complying with various quality inspection standards within the specified cost and labor-hour, work flow, methods and conditions must be provided and implemented. If working procedure changes in the manufacturing process, or the working methods and conditions change, the products complying with the above standards cannot be produced. 


\section{To increase efficiency}

The implementation of standardization can maximize productivity within the limited time in the production process and effectively utilize manpower and material resources to ensure product quality and improve work efficiency. The stabilization of product quality and the improvement of productivity can make en enterprise stand firm in the market.

\section{To reserve technology}

Work experience of enterprise employees can be kept through text or document to make sure the experience will not lose with staff turnover in future production or operation process.

\section{To prevent recurrence}

When old employees leave their posts, they will take away valuable post experience such as solutions and working skills. When the same problems occur in the future, if these methods and skills are not recorded, the production cannot resume. So, without standardization, product quality and time delay will be affected to some extent.

\section{Economic benefit of standardization}

Implementation of marketing standardization in large and medium-sized enterprises can bring ideal economic benefit. Implementation of standardization can make the enterprise give play to standard and optimal system benefit. This can not just improve the degree of the demand for standardized object, but also make the enterprise give play to the best functions so as to gain the optimal economic benefit. Without standard or without implementation of the standard, enterprise chaos is inevitable. Besides, the enterprise will soon be eliminated by the market full of fierce competitions. Therefore, marketing of large and medium-size enterprises breaks through traditional standard field for management standard, technical standard and safety standard. Thus, this enterprise will innovate in the fierce platform and then gain the best economic benefit.

\section{Effect and significance of standardization on marketing of large and medium-size enterprises}

The development of a large or medium-size enterprise cannot be separated from implementation of standardization. The process of standardization is a process of continuously improving product quality, management level, safety coefficient and economic benefit. Implementation of standardization is a kind of organized activities formulated and implemented by enterprises which take improving economic benefit as the objective and regard completing production, management, technology and marketing well as the main contents. Without the process of standardization, there are no superior management techniques and operation methods. So, the functions and effects of standardization means the objects which had no standards have standards. Through execution of the system, enterprises can gain the best order and status. Standardization is not just a process of shaping the soul of large and medium-sized enterprises, but also a process of sustainable development and harmonious development of enterprises. Thus, standardization is an important content and method to judge scientific management. Standardization has significant effects on improving products, process and services and eliminating technical limitations and shortcomings. Besides, it has important significance for sustainable development of large and medium-sized enterprises and improvement of economic benefit. Implementation of standardization is the pillar and foundation of all objects needing standards. So, implementation of standardization is of great significance for maintaining uniform actions and effective operation of large and medium-sized enterprises.

\section{Overview of effects and significance of standardization on marketing of large and medium-sized enterprises}

The effects of enterprise standardization on marketing of large and medium-sized enterprises not just lie in improving management, optimizing techniques and boosting operation safety coefficient, but also lie in improving economic benefit. Implementation of standardization makes large and 
medium-sized enterprises create conditions for standardized, scientific, systematical and uniform activities. Therefore, implementation of standardization by large and medium-sized enterprises is important basis for promoting sustainable development and scientific development.

\section{References}

[1] Cheng Qian, Service administration theory underway - overview of China's "service administration” from 2001 to 2004, Chinese Public Administration, 2005

[2] Huang Yong, Enhancement of renewable resource standardization and promotion of resource-economical and environment-friendly society with circular economy, Collection of academic paper about standardization in memory of the 39th "world standard day", 2008

[3] Li Kecheng, China's standardization work after joining WTO , Collection of prize-winning paper about standardization in Hubei Province, 2004

[4] Kuang Hua'an, Zhang Houdong, Quality standardization becoming another focus in international competitions, China metallurgical News, 2008

[5] WangYicheng, Energy conservation, emission reduction and standardization, Transformation of economic development mode and self-dependent innovation - the 12th annual conference of China Association for Science and Technology (Vol.1), 2010

[6] Sun Honglin, Practice-based standardization is the key point, Collection of academic paper about standardization in 2005, 2005 